\title{
RISK ASSESSMENT PADA PEKERJA PENGELASAN PERKAPALAN DENGAN PENDEKATAN JOB SAFETY ANALYSIS
}

\author{
Dewi Wulandari, Noeroel Widajati \\ Departemen Keselamatan dan Kesehatan Kerja \\ Fakultas Kesehatan Masyarakat, Universitas Airlangga \\ Email: dewiqwoelandjari21@gmail.com
}

\begin{abstract}
PT DUMAS Tanjung Perak Shipyards develop into a company that is also engaged in the construction of new vessels. The process construction of ships is a activities performed starting from a vessel until with the delivery of the product of a ship to the owner. To the process of grafting blocks the activity of a ship can not be separated from the activity of welding. Where in the process of welding should not be there was a mistake as small as any fine is crack, over heat, and so on. Activity welding done di a place like welding room open, enclosed space and at high altitude. The study is done by means of interviews and direct observation. The purpose of this research is to identify danger activity welding, risk assessment from danger welding at open space, enclosed space and in the height of that they can even detect control mechanisms. This research in a job safety analysis to identify potential. The results from workers welding in PT. Dumas Tanjung Perak Shipyards namely hit a work piece, scratched and hit hard a hammer slag, truncated, slipped, stung electricity, burning, stung fire, fell, spark fire, punctured, fall down from a height, faint, poisoning, and hit by a work piece. The impact of danger what will happen is destructive the eyes and skin, respiratory disorders, to generate explosion or fires, death, injured, and burns on the body. Engineering control (safety line and LOTO), subsisting control (safety talk and training), and the self protection (helmet, wear pack, safety shoes, goggles).
\end{abstract}

Keywords: Job Analysis Safety, hazard identification, risk assessment, risk control

\begin{abstract}
ABSTRAK
PT. Dumas Tanjung Perak Shipyard berkembang menjadi perusahaan yang juga bergerak dalam pembangunan kapal baru. Proses pembangunan kapal merupakan suatu aktivitas yang dilakukan mulai dari perencanaan kapal sampai dengan penyerahan produk kapal kepada pemilik kapal. Pada proses aktivitas penyambungan blok-blok kapal tidak lepas dari aktivitas pengelasan. Proses pengelasan tidak boleh ada kesalahan sekecil apapun baik merupakan crack, over heat, dan sebagainya. Aktivitas pengelasan dilakukan di berbagai tempat seperti pengelasan di ruang terbuka, ruang tertutup dan di tempat ketinggian. Penelitian ini dilakukan dengan cara wawancara dan observasi langsung. Tujuan dari penelitian ini adalah untuk mengidentifikasi bahaya aktivitas pengelasan, menilai risiko dari bahaya pengelasan pada ruang terbuka, ruang tertutup dan di tempat ketinggian sehingga dapat menentukan cara pengendalian. Penelitian ini menggunakan metode Job Safety Analysis. Hasil dari pengambilan data ini didapat PT. DUMAS Tanjung Perak Shipyards memiliki risiko bahaya pada aktivitas pengelasan yaitu berupa terbentur material kerja, terkena pukulan palu terak, terpotong mesin gerinda, terpeleset, kesetrum listrik, kebakaran, terkena api, jatuh dari ketinggian, terkena percikan benda, tertusuk serpihan besi, tidak sadarkan diri, keracunan gas dan kejatuhan material. Dampak bahaya yang akan terjadi adalah kerusakan mata dan kulit, gangguan pernapasan, menimbulkan ledakan atau kebakaran, kematian, cidera pada tubuh, dan luka bakar pada tubuh pekerja. Pengendalian yang dilakukan berdasarkan hierarki pengendalian yaitu engineering control (safety line dan LOTO), administrative control (safety talk dan pelatihan), dan alat pelindung diri (helmet, wear pack, safety shoes, goggles).
\end{abstract}

Kata kunci: Job Safety Analysis, identifikasi bahaya, penilaian risiko, pengendalian risiko

\section{PENDAHULUAN}

Di era globalisasi sekarang ini sangat diperlukan teknologi yang maju agar memenuhi kebutuhan manusia secara menyeluruh, terkadang tanpa kita sadari tidak adanya pengendalian yang baik menyebabkan kerugian bagi manusia itu sendiri. Pada penggunaan teknologi tidak dapat dihindari maka pada era industrialiasi sekarang ini proses transformasi di dalam teknologi tidak dapat dicegah perkembangannya. Dengan adanya penggunaan teknologi maju akan memengaruhi peningkatan penggunaan bahan-bahan yang mempunyai potensi bahaya sesuai dengan kebutuhan industrial saat ini. Pada penggunaan teknologi yang maju akan memberikan kemudahan bagi pengguna, namun juga akan memberikan dampak yang tidak dapat dihindari yaitu bertambahnya jumlah risiko bahaya dan ragam 
sumber kecelakaan bagi pengguna teknologi itu sendiri.

Perusahaan yang modern dan memiliki teknologi maju di samping mempunyai dampak faktor lingkungan kerja yang tidak memenuhi standar keselamatan dan kesehatan kerja, pada proses kegiatan kerja yang kurang aman, dan sistem manajemen kerja yang semakin rumit dan modernisasi akan mengancam keselamatan dan kesehatan kerja. Salah satunya industri di dalam perkapalan yang ada di Indonesia. Industri galangan perkapalan akhir-akhir ini melakukan pengembangan yang cukup signifikan, ini dibuktikan dengan banyaknya order pembuatan kapal baru, khususnya di galangan kapal yang ada di Surabaya.

PT. Dumas Tanjung Perak Shipyard didirikan di Surabaya, Jawa Timur pada 10 Januari 1973. Sejalan dengan pertumbuhan dan meningkatnya permintaan kapal di pasar lokal dalam negeri PT. Dumas Tanjung Perak Shipyards berkembang menjadi perusahaan yang juga bergerak dalam pembangunan kapal baru (new building). Membawa visi menjadi galangan kapal dengan kualitas internasional maka PT. Dumas Tanjung Perak Shipyard meningkatkan mutu pelayanan demi kepuasan pelanggan. Oleh karena itu, PT. Dumas Tanjung Perak Shipyard kini menjadi salah satu galangan kapal terbesar di Surabaya. PT. Dumas Tanjung Perak Shipyard membangun kapal baru untuk pertama kalinya pada tahun 1980. Sejak saat itu, perusahaan terus aktif menyediakan jasa sebagai shipbuilder.

Proses pembangunan kapal merupakan suatu aktivitas yang dilakukan mulai dari perencanaan kapal (desain) sampai dengan penyerahan produk kapal kepada pemilik kapal. Pembangunan kapal ini dilakukan melalui suatu tahapan proses yang salah satunya yaitu pembentukan blok-blok badan kapal yang dilakukan di building berth. Kemudian blokblok tersebut disatukan menjadi blok yang lebih besar di assembly area. Aktivitas penyambungan blok-blok kapal tersebut tidak lepas dari aktivitas pengelasan. Proses pengelasan ini sangat penting dikarenakan untuk melakukan join bagian-bagian hull kapal.

Dimana dalam proses pengelasan (welding) tidak boleh ada kesalahan sekecil apapun baik merupakan crack, over heat, dan sebagainya. Proses pengelasan ini merupakan bagian yang amat vital dalam proses pembangunan kapal. Jenis bahaya yang terjadi akibat pengelasan yaitu terkena radiasi sinar ultraviolet dan infra merah, terhirup asap (fume) yang ada pada pengelasan, kebakaran, tersetrum listrik. Oleh karena itu untuk mengetahui bahaya apa saja yang ada pada aktivitas pengelasan serta pengendaliannya.

Salah satu cara untuk mencegah kecelakaan di tempat kerja adalah dengan menetapkan dan menyusun prosedur pekerjaan dan melatih semua pekerja untuk menerapkan metode kerja yang efisien dan aman. Menyusun prosedur kerja yang benar dan aman merupakan salah satu keuntungan dari penerapan Job Safety Analysis. Job Safety Analysis atau Job Hazard merupakan upaya untuk mempelajari, menganalisa dan serta pencatatan tiap-tiap urutan langkah kerja suatu pekerjaan, dilanjutkan dengan mengidentifikasi potensi-potensi bahaya di dalamnya kemudian menyelesaikan dengan menentukan upaya terbaik di perusahaan untuk mengurangi ataupun menghilangkan atau mengendalikan bahaya-bahaya pada pekerjaan yang terdapat di perusahaan tersebut. Sehingga dengan penerapan Job Safety Analysis tersebut diharapkan dapat mencegah kecelakaan yang akan menimbulkan kerugian bagi perusahaan. Pada penelitian ini menggunakan metode $J S A$ agar memudahkan proses mengidentifikasi, menganalisis potensi bahaya dan melakukan evaluasi risiko bahaya keselamatan kerja. Pembuatan $J S A$ ini disesuaikan dengan kondisi sumber daya perusahaan tersebut.

Undang-Undang Republik Indonesia Nomor 1 Tahun 1970 merupakan dasar hukum tentang Keselamatan Kerja di Indonesia. Undang-undang ini membahas mengenai hak dan kewajiban tenaga kerja, dan juga persyaratan keselamatan kerja yang harus diterapkan dalam tiap-tiap perusahaan. Hukum lainnya yang terkait adalah Undang-Undang No.13 tahun 2003 yaitu mengenai Ketenagakerjaan, pasal 86 dalam Undang-Undang ini menyebutkan bahwa setiap organisasi wajib menerapkan upaya keselamatan dan kesehatan kerja untuk melindungi keselamatan tenaga kerja, sedangkan pasal 87 dalam Undang-Undang ini menyebutkan bahwa setiap perusahaan diwajibkan memiliki SMK3 yang terintegrasi dengan bagian manajemen perusahaan lainnya. Untuk mematuhi hukum di Indonesia dan untuk meminimalisasikan kecelakaan kerja di perusahaan maka, diperlukan upaya identifikasi potensi bahaya yang ada di perusahaan. Identifikasi potensi bahaya dan juga pengendaliannya dapat menggunakan metode Job Safety Analysis.

Selama penelitian dari 15 Agustus 2016 sampai dengan 14 September 2016 jumlah data kecelakaan yang berhubungan dengan proses kegiatan pengelasan di PT DUMAS Tanjung Perak Shipyards 
Surabaya sebanyak 6 kasus, diantaranya 1 orang terkena luka bakar pada tangan sampai melepuh, 2 orang terkena serpihan gram gerinda yang mengenai mata, 1 orang terkena luka bakar di wajah, dan 2 orang terkena luka bakar pada lengannya. Oleh karena itu untuk mengetahui bahaya apa saja yang ada pada aktivitas pengelasan serta pengendaliannya. Mengidentifikasi bahaya dan pengendaliannya pada aktivitas pengelasan dengan menggunakan metode Job Safety Analysis. Tujuan dari penelitian ini adalah mengidentifikasi bahaya di pengelasan, penilaian risiko dan mempelajari pengendalian risiko di pengelasan, pemotongan dan gerinda kapal di PT. DUMAS Tanjung Perak Shipyards Surabaya.

\section{METODE}

Tahapan dalam penelitian dengan metode $J o b$ Safety Analysis pada proses pengelasan di perkapalan di PT DUMAS Tanjung Perak Shipyards Surabaya adalah sebagai berikut.

Tahap pertama dalam penelitian ini dengan mengetahui terlebih dahulu proses pekerjaan pada aktivitas pengelasan. Langkah-langkah tersebut didapatkan ketika wawancara dan observasi langsung yang dilakukan di galangan kapal. Tahap kedua adalah mengidentifikasi potensi bahaya kecelakaan pada proses pengelasan di setiap aktivitasnya.

Tahap ketiga melakukan penilaian dengan menilai seberapa besar konsekuensi, pemaparan, dan kemungkinan risiko keselamatan di tempat kerja. Penilaian tersebut menggunakan penentuan skala konsekuensi, pemaparan, dan kemungkinan menggunakan tabel tertentu. Tahap keempat yaitu setelah risiko bahaya keselamatan diidentifikasi, melakukan penyusunan tingkat risiko bahaya keselamatan kerja dengan menggunakan parameter hasil perkalian nilai konsekuensi, paparan, dan

Tabel 1. Metode Semi Kuantitatif

\begin{tabular}{|c|c|c|}
\hline Konsekuensi & Penjelasan & Score \\
\hline Catastrophe & $\begin{array}{l}\text { Bencana besar: fasilitas mengalami kerusakan parah, kegiatan dihentikan, } \\
\text { terjadi kerusakan lingkungan parah (kerugian }>\$ 1 \text { million) }\end{array}$ & 100 \\
\hline Disaster & $\begin{array}{l}\text { Bencana: menimbulkan kematian, terjadi kerusakan kecil dan permanen pada } \\
\text { lingkungan (kerugian } \$ 500.000-\$ 1000.000) \text {. }\end{array}$ & 50 \\
\hline Very serious & $\begin{array}{l}\text { Sangat serius: cacat permanen, terjadi kerusakan tidak permanen pada } \\
\text { lingkungan (kerugian } \$ 50.000-\$ 500.000 \text { ). }\end{array}$ & 25 \\
\hline Serious & $\begin{array}{l}\text { Serius: terjadi cidera dan penyakit bukan permanen, berdampak sedikit bagi } \\
\text { lingkungan (kerugian } \$ 5.000-\$ 50.000 \text { ) }\end{array}$ & 15 \\
\hline Important & $\begin{array}{l}\text { Penting: butuh tindakan medis, terjadi emisi buangan, tidak menimbulkan } \\
\text { kerusakan lingkungan (kerugian } \$ 500-\$ 5.000) \text {. }\end{array}$ & 5 \\
\hline Noticeable & $\begin{array}{l}\text { Tampak: cidera dan penyakit ringan/ memar, tidak terjadi kerusakan } \\
\text { lingkungan (kerugian }<\$ 500) \text {. }\end{array}$ & 1 \\
\hline Pemaparan & Penjelasan & Score \\
\hline Continuously & Sering sekali: pemaparan yang sering terjadi. & 10 \\
\hline Frequently & Sering: dalam sehari terjadi sekali & 6 \\
\hline Occasionally & Kadang-kadang: Seminggu sampai sebulan terjadi sekali & 3 \\
\hline Infrequent & Tidak sering: sebulan sampai setahun terjadi sekali & 2 \\
\hline Rare & Jarang: kapanpun kejadiannya dapat diketahui & 1 \\
\hline Very rare & Sangat jarang: kejadiannya tidak diketahui & 0,5 \\
\hline Kemungkinan & Penjelasan & Score \\
\hline Almost certain & Sering terjadi: sering terjadi kejadian & 10 \\
\hline Likely & Cenderung terjadi: terjadi kecelakaan 50:50 & 6 \\
\hline Unusual but possible & Tidak biasa: tidak terbiasa terjadi kecelakaan & 3 \\
\hline Remotely but possible & Kemungkinan kecil: kecil terjadi kecelakaan & 1 \\
\hline Conceivable & Jarang terjadi: selama pemaparan tidak terjadi kecelakaan & 0,5 \\
\hline Practically impossible & Hampir tidak mungkin terjadi & 0,1 \\
\hline
\end{tabular}


kemungkinan sehingga didapatkan hasilnya. Hasil dari perkalian variabel tersebut akan dibagi ke dalam beberapa kategori, yaitu Very High, priority 1, Substansial, priority 3, dan Acceptable (AS/NZS 4360:199). Berikut ini merupakan tabel metode semi kuantitatif terbagi menjadi 3 unsur. Tahap terakhir adalah menentukan tindakan pengendalian risiko dan merupakan salah satu upaya untuk mengurangi atau menghilangkan paparan yang berbahaya di lingkungan kerja. Kegiatan dalam pengendalian tersebut yaitu: eliminasi, substitusi, rekayasa teknis, administrative, dan terakhir alat pelindung diri.

\section{HASIL}

PT. Dumas Tanjung Perak Shipyard peduli dan berkomitmen terhadap permasalahan lingkungan sesuai dengan standar pengelolaan lingkungan secara umum dan pengelolaan lingkungan bidang galangan secara khusus, menerapkan seluruh klausal yang ditetapkan dengan standar sistem manajemen mutu ISO 9001:2008.

Bahaya fisik dan mekanik adalah sumber utama kecelakaan di banyak industri, tidak terkecuali industri galangan kapal. Bahaya tidak terhindarkan sering kali ditemui dalam pekerjaan di lapangan, namun seiring berjalannya waktu maka manusia mengembangkan metode dan prosedur keamanan untuk meminimalisir risiko tersebut. Metode dan prosedur tersebut diatur dalam sistem manajemen keselamatan dan kesehatan kerja.

PT. DUMAS Tanjung Perak Shipyard berkomitmen untuk meningkatkan mutu keselamatan kerja dengan pengendalian bahaya dan risiko keselamatan dan kesehatan kerja dengan kepatuhan terhadap peraturan keselamatan dan kesehatan kerja. Keterlibatan secara menyeluruh dari pemangku kepentingan dalam menciptakan kondisi dan lingkungan kerja yang dapat mencegah dan mengurangi kecelakaan kerja serta penyakit akibat kerja. Tercapainya zero accident dengan menciptakan lingkungan yang BESARI (Bersih, Efisien, Sehat, Aman, Rapi) untuk meningkatkan produktivitas dengan senantiasa melakukan perbaikan berkelanjutan.

Kegiatan pengendalian risiko di perusahaan yang telah dilakukan di pengelasan antara lain: sebelum melakukan aktivitas pekerjaan pengelasan setiap hari, pada hari Senin dan Jumat pagi dilakukan safety talk pada pekerja yang berisikan tentang pemberitahuan atau menginformasikan bahayabahaya yang berpotensi kecelakaan di tempat kerja serta tindakan pencegahan yang harus dilakukan. Bagi pekerja yang baru atau pindahan dari tempat kerja yang sebelumnya dilakukan training selama satu bulan agar dapat mengenali potensi bahaya di tempat kerja dan bagaimana cara pengendalian. Bila ada pekerja yang mendapatkan tugas pada tempat-tempat berpotensi bahaya tinggi, maka pekerja tersebut meminta Surat Izin Kerja Berbahaya (SIKB) atau Work Permit kepada pihak P2K3 perusahaan. Tempat yang berpotensi bahaya tinggi yaitu pengelasan pada tempat-tempat yang tinggi dan pada ruang tertutup di dalam kapal.

Bagi pihak sub kontraktor yang bekerja sama dengan perusahaan dalam pembuatan kapal sebelum kerja dimulai harus mempunyai Surat Izin Kerja (SIK) dan setelah mendapatkannya barulah akan dijelaskan bahaya yang ada di tempat kerja oleh pihak yang berwenang yaitu K3 perusahaan. Bentuk pengarahan atau informasinya berupa JSA. Pada pelaksanaan aktivitas pekerjaan pengelasan selalu dilakukan pengawasan setiap hari oleh K3. Tentu saja, bila mengandalkan pengawasan saja masih kurang dalam pengendalian risiko bahaya bila kesadaran para pekerjanya untuk melindungi diri sendiri masih kurang. Selain pengendalian pada manusia ada juga pengendalian untuk peralatan kerja, yaitu: melakukan kalibrasi alat, melakukan perawatan atau pemeliharaan alat-alat kerja, serta melakukan peremajaan peralatan yang sudah rusak diganti yang baru. Maka dari itu kewajiban itu sudah disepakati oleh pihak perusahaan dalam upaya melindungi para pekerja sehingga dapat mengurangi bahaya dan risiko kerja, dan melindungi keselamatan pekerja itu sendiri dan orang di sekitarnya.

Adapun bentuk alat pelindung diri yang disediakan oleh perusahaan adalah: safety helmet (berfungsi melindungi kepala dari benda yang bisa mengenai kepala), safety belt (alat pengaman ketika menggunakan alat transportasi, safety shoes (melindungi kaki dari benda tajam atau benda panas dan cairan kimia), sarung tangan (melindungi tangan dari serpihan benda-benda tajam besi dan situasi lainnya), safety harness (diwajibkan menggunakan alat ini pada ketinggian lebih dari 1,5 meter), ear plug/ear muff (melindungi telinga dari kebisingan), masker (melindungi dari debu) tergantung pada tempat kerja, safety spectacles, goggles, face shields (pelindung mata sampai ke wajah). Walaupun demikian semua metode pengendalian tersebut tidak lantas menurunkan bahaya dan risiko pada titik nol, artinya para pekerja masih besar kemungkinannya terpajan terhadap bahaya di tempat kerja. Untuk 
itu perlu komitmen yang kuat dari sumber daya manusia atau manajemen dan kesadaran para pekerja akan penggunaan alat pelindung diri dalam setiap bekerja.

Pada penelitian ini dalam pengambilan data bersumber dari data primer dan data sekunder. Maka dari itu ada beberapa jenis kegiatan pengelasan dan tahapannya. Dimulai dengan mengidentifikasi risiko keselamatan pengelasan di ruang terbuka dengan menggunakan las listrik dan las gas. Pada tahapan pengelasan las listrik dan las gas di ruang terbuka mempunyai beberapa perbedaan dalam setiap aktivitas pekerjaannya. Tahap pertama dalam pengelasan terbuka yaitu: (1) Menghubungkan panel alat ke benda kerja, (2) Menghidupkan unit dari panel box pengelasan dan penyesuaian arus listrik yang digunakan. Untuk mengelas dengan menggunakan las listrik, bila pekerja menggunakan las gas yaitu dengan mempersiapkan tabung gas asitelin dan oksigen terlebih dahulu, menyalakan gas tersebut. Tahap kedua aktivitas pengelasan yaitu: melakukan pengerjaan las itu sendiri. Tahap ketiga tahapan perapian atau finishing yaitu: (1) Merapikan benda kerja dengan palu terak, (2) Merapikan material kerja dengan sikat besi khusus, (3) Merapikan material kerja dengan mesin gerinda,
(4) Merapikan mesin las listrik dengan cara memutuskan sumber arus listrik dan alat las tabung gas, (6) Memindahkan material kerja yang sudah dilas, (7) Membersihkan tempat kerja dari serpihan dan potongan kecil besi.

Identifikasi risiko pengelasan di tempat ketinggian. Tahap persiapan yaitu menaiki tangga atau scaffolding. Tahap pengerjaan pengelasan yaitu melakukan pengelasan dengan mesin las. Tahap ketiga perapian atau finishing mempunyai tahapan lagi yaitu: (1) Melakukan perapian dengan palu terak, (2) Membersihkan material kerja dari serpihan dan potongan material, (3) Turun tangga atau scaffolding.

Identifikasi risiko keselamatan pengelasan di ruang tertutup. Tahap pertama persiapan yaitu memasuki ruang dalam kapal. Tahap kedua pengerjaan pengelasan dengan melakukan pengelasan dengan las listrik maupun las gas. Tahap ketiga melakukan perapian dan finishing, pada tahap ini mempunyai beberapa tahapan lagi yaitu: (1) Melakukan perapian dengan menggunakan palu terak, (2) Membersihkan area kerja dari potongan atau serpihan benda kerja, (3) Keluar dari ruang di dalam kapal.

Tabel 2. Analisis Risiko Keselamatan Pengelasan pada Tempat Terbuka dengan Las

\begin{tabular}{|c|c|c|c|c|c|c|c|c|}
\hline \multirow{2}{*}{$\begin{array}{c}\text { Tahap } \\
\text { Pekerjaan }\end{array}$} & \multirow{2}{*}{$\begin{array}{c}\text { Identifikasi } \\
\text { Bahaya }\end{array}$} & \multirow{2}{*}{ Bahaya } & \multicolumn{4}{|c|}{ Analisis Risiko } & \multirow{2}{*}{ Kategori } & \multirow{2}{*}{ Pengendalian } \\
\hline & & & $\mathbf{C}$ & $\mathbf{E}$ & $\mathbf{L}$ & Skor & & \\
\hline \multicolumn{9}{|c|}{ Tahap Persiapan Pengelasan } \\
\hline \multirow{2}{*}{$\begin{array}{l}\text { Menghubungkan } \\
\text { grounding ke } \\
\text { material kerja }\end{array}$} & $\begin{array}{l}\text { Kondisi tempat } \\
\text { kerja yang tidak } \\
\text { rapi }\end{array}$ & $\begin{array}{l}\text { Terbentur } \\
\text { benda }\end{array}$ & 1 & 10 & 3 & 30 & Priority 3 & $\begin{array}{l}\text { Memakai helmet, safety } \\
\text { shoes, memasangkan warning } \\
\text { sign dan safety line di area } \\
\text { kerja serta melakukan safety } \\
\text { talk sebelum kerja }\end{array}$ \\
\hline & $\begin{array}{l}\text { Kondisi tempat } \\
\text { kerja yang licin }\end{array}$ & Terpeleset & 2 & 3 & 3 & 18 & Acceptable & $\begin{array}{l}\text { Memakai helmet, safety } \\
\text { shoes, memasangkan warning } \\
\text { sign dan safety line di area } \\
\text { kerja serta melakukan safety } \\
\text { talk sebelum kerja }\end{array}$ \\
\hline \multirow{2}{*}{$\begin{array}{l}\text { Menghidupkan } \\
\text { Panel Box } \\
\text { pengelasan dan } \\
\text { menyesuaikan } \\
\text { arus listrik }\end{array}$} & $\begin{array}{l}\text { Kondisi } \\
\text { kabel yang } \\
\text { tidak terawat } \\
\text { (terkelupas) }\end{array}$ & $\begin{array}{l}\text { Tersengat } \\
\text { listrik }\end{array}$ & 50 & 2 & 1 & 100 & Substantial & $\begin{array}{l}\text { Dipasang papan pijakan di } \\
\text { area basah, memakai sarung } \\
\text { tangan, safety shoes, helmet, } \\
\text { wear pack pemeliharaan } \\
\text { peralatan secara berkala }\end{array}$ \\
\hline & $\begin{array}{l}\text { Posisi kabel } \\
\text { yang tidak rapi }\end{array}$ & Terjatuh & 15 & 1 & 3 & 45 & Priority 3 & $\begin{array}{l}\text { Merapikan kabel yang } \\
\text { berserakan di area kerja agar } \\
\text { tidak mengganggu akses } \\
\text { jalan, memasang warning } \\
\text { sign dan house keeping rutin }\end{array}$ \\
\hline
\end{tabular}




\begin{tabular}{|c|c|c|c|c|c|c|c|c|}
\hline Tahap Penge & Pengelasan & & & & & & & \\
\hline \multirow{6}{*}{$\begin{array}{l}\text { Mengelas } \\
\text { material kerja } \\
\text { dengan las } \\
\text { listrik maupun } \\
\text { dengan gas }\end{array}$} & $\begin{array}{l}\text { Posisi jari } \\
\text { tangan yang } \\
\text { salah saat } \\
\text { menjepit } \\
\text { elektroda }\end{array}$ & $\begin{array}{l}\text { Terjepit } \\
\text { Holder }\end{array}$ & 1 & 6 & 10 & 60 & Priority 3 & $\begin{array}{l}\text { Arahkan tangan dengan posisi } \\
\text { yang benar, memakai goggles, } \\
\text { sarung tangan, dan helmet }\end{array}$ \\
\hline & Percikan api las & $\begin{array}{l}\text { Terkena } \\
\text { percikan } \\
\text { api }\end{array}$ & 5 & 10 & 3 & 150 & Substantial & $\begin{array}{l}\text { Memakai goggles, face shield, } \\
\text { helmet, safety shoes dan } \\
\text { harus memakai wear pack } \\
\text { pelindung badan }\end{array}$ \\
\hline & $\begin{array}{l}\text { Percikan api las } \\
\text { mengenai bahan } \\
\text { yang mudah } \\
\text { terbakar }\end{array}$ & Terbakar & 50 & 1 & 3 & 150 & Substantial & $\begin{array}{l}\text { Sediakan APAR dan } \\
\text { menyediakan tempat untuk } \\
\text { peralatan dan material yang } \\
\text { mudah terbakar }\end{array}$ \\
\hline & $\begin{array}{l}\text { Kondisi } \\
\text { kabel yang } \\
\text { tidak terawat } \\
\text { (terkelupas) atau } \\
\text { area kerja basah }\end{array}$ & $\begin{array}{l}\text { Tersengat } \\
\text { listrik }\end{array}$ & 50 & 2 & 3 & 300 & Priority 1 & $\begin{array}{l}\text { Dipasang papan pijakan di } \\
\text { area basah, memakai sarung } \\
\text { tangan, safety shoes, helmet, } \\
\text { wear pack pemeliharaan } \\
\text { peralatan secara berkala }\end{array}$ \\
\hline & $\begin{array}{l}\text { Saat menjepit } \\
\text { benda kerja } \\
\text { posisi jari } \\
\text { tangan salah }\end{array}$ & Terjepit & 5 & 10 & 1 & 50 & Priority 3 & $\begin{array}{l}\text { Arahkan tangan dengan posisi } \\
\text { yang benar, memakai goggles, } \\
\text { sarung tangan, dan helmet }\end{array}$ \\
\hline & $\begin{array}{l}\text { Posisi kabel } \\
\text { yang tidak rapi }\end{array}$ & Terjatuh & 5 & 2 & 6 & 60 & Priority 3 & $\begin{array}{l}\text { Merapikan kabel yang } \\
\text { berserakan di area kerja agar } \\
\text { tidak mengganggu akses } \\
\text { jalan, memasang warning } \\
\text { sign dan house keeping rutin }\end{array}$ \\
\hline \multicolumn{9}{|c|}{ Tahap Perapian dan Finishing } \\
\hline \multirow{3}{*}{$\begin{array}{l}\text { Merapikan } \\
\text { material kerja } \\
\text { yang dilas } \\
\text { dengan palu }\end{array}$} & $\begin{array}{l}\text { Posisi jari } \\
\text { tangan yang } \\
\text { salah }\end{array}$ & Tergores & 5 & 2 & 6 & 60 & Priority 3 & $\begin{array}{l}\text { Menjaga jarak aman saat } \\
\text { bekerja, konsentrasi, dan } \\
\text { berhati-hati saat bekerja, } \\
\text { memakai wear pack, helmet, } \\
\text { safety shoes, dan sarung } \\
\text { tangan. }\end{array}$ \\
\hline & $\begin{array}{l}\text { Percikan benda } \\
\text { kecil }\end{array}$ & $\begin{array}{l}\text { Terkena } \\
\text { percikan } \\
\text { benda } \\
\text { kecil }\end{array}$ & 5 & 10 & 3 & 150 & Substantial & $\begin{array}{l}\text { Memakai goggles, face shield, } \\
\text { helmet, safety shoes, sarung } \\
\text { tangan dan harus memakai } \\
\text { wear pack pelindung }\end{array}$ \\
\hline & $\begin{array}{l}\text { Posisi kabel } \\
\text { yang tidak rapi }\end{array}$ & Terjatuh & 5 & 2 & 6 & 60 & Priority 3 & $\begin{array}{l}\text { Merapikan kabel yang } \\
\text { berserakan di area kerja agar } \\
\text { tidak mengganggu akses } \\
\text { jalan, memasang warning } \\
\text { sign dan rutin }\end{array}$ \\
\hline $\begin{array}{l}\text { Merapikan } \\
\text { material kerja } \\
\text { dengan sikat } \\
\text { baja }\end{array}$ & $\begin{array}{l}\text { Posisi jari } \\
\text { tangan yang } \\
\text { salah }\end{array}$ & Tertusuk & 5 & 2 & 6 & 60 & Priority 3 & $\begin{array}{l}\text { Memakai helmet, safety } \\
\text { shoes, sarung tangan dan } \\
\text { harus memakai wear pack } \\
\text { pelindung }\end{array}$ \\
\hline
\end{tabular}




\begin{tabular}{|c|c|c|c|c|c|c|c|c|}
\hline \multirow{4}{*}{$\begin{array}{l}\text { Merapikan } \\
\text { material kerja } \\
\text { yang dilas } \\
\text { dengan mesin } \\
\text { gerinda }\end{array}$} & $\begin{array}{l}\text { Posisi jari } \\
\text { tangan yang } \\
\text { salah }\end{array}$ & Tergores & 5 & 3 & 3 & 45 & Priority 3 & $\begin{array}{l}\text { Menjaga jarak aman saat } \\
\text { bekerja, konsentrasi, dan } \\
\text { berhati-hati saat bekerja, } \\
\text { memakai wear pack, helmet, } \\
\text { safety shoes, dan sarung } \\
\text { tangan }\end{array}$ \\
\hline & $\begin{array}{l}\text { Percikan api dari } \\
\text { benda kerja }\end{array}$ & $\begin{array}{l}\text { Terkena } \\
\text { percikan } \\
\text { api }\end{array}$ & 1 & 3 & 10 & 30 & Priority 3 & $\begin{array}{l}\text { Memakai goggles, face shield, } \\
\text { helmet, safety shoes, sarung } \\
\text { tangan dan harus memakai } \\
\text { wear pack pelindung }\end{array}$ \\
\hline & $\begin{array}{l}\text { Posisi kabel } \\
\text { yang tidak rapi }\end{array}$ & Terjatuh & 1 & 10 & 3 & 30 & Priority 3 & $\begin{array}{l}\text { Merapikan kabel yang } \\
\text { berserakan di area kerja agar } \\
\text { tidak mengganggu akses } \\
\text { jalan, memasang warning } \\
\text { sign dan house keeping rutin }\end{array}$ \\
\hline & $\begin{array}{l}\text { Kabel terkelupas } \\
\text { atau tidak } \\
\text { terpelihara }\end{array}$ & $\begin{array}{l}\text { Tersengat } \\
\text { listrik }\end{array}$ & 15 & 1 & 3 & 45 & Priority 3 & $\begin{array}{l}\text { Dipasang papan pijakan di } \\
\text { area basah, memakai sarung } \\
\text { tangan, safety shoes, helmet, } \\
\text { wear pack pemeliharaan } \\
\text { peralatan secara berkala }\end{array}$ \\
\hline \multirow{2}{*}{$\begin{array}{l}\text { Mematikan } \\
\text { hubungan arus } \\
\text { dengan sumber } \\
\text { arus listrik }\end{array}$} & $\begin{array}{l}\text { Kondisi kabel } \\
\text { yang tidak } \\
\text { terawat atau area } \\
\text { kerja basah }\end{array}$ & $\begin{array}{l}\text { Tersengat } \\
\text { listrik }\end{array}$ & 50 & 1 & 3 & 150 & Substantial & $\begin{array}{l}\text { Dipasang papan pijakan di } \\
\text { area basah, memakai sarung } \\
\text { tangan, safety shoes, helmet, } \\
\text { wear pack pemeliharaan } \\
\text { peralatan secara berkala }\end{array}$ \\
\hline & $\begin{array}{l}\text { Posisi kabel } \\
\text { yang tidak rapi }\end{array}$ & Terjatuh & 1 & 10 & 3 & 30 & Priority 3 & $\begin{array}{l}\text { Merapikan kabel yang } \\
\text { berserakan di area kerja agar } \\
\text { tidak mengganggu akses } \\
\text { jalan, memasang warning } \\
\text { sign dan house keeping rutin }\end{array}$ \\
\hline \multirow{2}{*}{$\begin{array}{l}\text { Memindahkan } \\
\text { material kerja } \\
\text { yang sudah dilas }\end{array}$} & $\begin{array}{l}\text { Jari tangan } \\
\text { tergores sisi } \\
\text { benda kerja } \\
\text { yang tajam }\end{array}$ & Tergores & 1 & 6 & 6 & 36 & Priority 3 & $\begin{array}{l}\text { Menjaga jarak aman saat } \\
\text { bekerja, konsentrasi, dan } \\
\text { berhati-hati saat bekerja, } \\
\text { memakai wear pack, helmet, } \\
\text { safety shoes, dan sarung } \\
\text { tangan }\end{array}$ \\
\hline & $\begin{array}{l}\text { Benda kerja } \\
\text { yang diangkat } \\
\text { terjatuh }\end{array}$ & Tertimpa & 5 & 6 & 3 & 90 & Substantial & $\begin{array}{l}\text { Koordinasi dengan pekerja } \\
\text { lain, konsentrasi dan berhati- } \\
\text { hati saat kerja serta memakai } \\
\text { wear pack, helmet, safety } \\
\text { shoes, sarung tangan }\end{array}$ \\
\hline $\begin{array}{l}\text { Membersihkan } \\
\text { tempat kerja } \\
\text { dari serpihan } \\
\text { material kerja }\end{array}$ & $\begin{array}{l}\text { Potongan atau } \\
\text { serpihan benda } \\
\text { kerja yang tajam }\end{array}$ & Tertusuk & 1 & 6 & 6 & 36 & Priority 3 & $\begin{array}{l}\text { Memakai helmet, safety } \\
\text { shoes, sarung tangan dan } \\
\text { harus memakai wear pack } \\
\text { pelindung }\end{array}$ \\
\hline
\end{tabular}


Tabel 3. Analisis Risiko Keselamatan Pengelasan pada Tempat Tinggi dengan Las

\begin{tabular}{|c|c|c|c|c|c|c|c|c|}
\hline \multirow{2}{*}{$\begin{array}{c}\text { Tahap } \\
\text { Pekerjaan }\end{array}$} & \multirow{2}{*}{$\begin{array}{c}\text { Identifikasi } \\
\text { Bahaya }\end{array}$} & \multirow{2}{*}{ Bahaya } & \multicolumn{4}{|c|}{ Analisis Risiko } & \multirow{2}{*}{ Kategori } & \multirow{2}{*}{ Pengendalian } \\
\hline & & & $\mathrm{C}$ & $\mathbf{E}$ & $\mathbf{L}$ & Skor & & \\
\hline \multicolumn{9}{|c|}{ Tahap Persiapan Pengelasan } \\
\hline \multirow{4}{*}{$\begin{array}{l}\text { Menaiki tangga } \\
\text { atau scaffolding }\end{array}$} & $\begin{array}{l}\text { Kondisi di } \\
\text { bawah tempat } \\
\text { kerja licin } \\
\text { karena air }\end{array}$ & Terpeleset & 1 & 2 & 3 & 6 & Acceptable & $\begin{array}{l}\text { Memakai helmet, safety } \\
\text { shoes, memasangkan warning } \\
\text { sign dan safety line di area } \\
\text { kerja serta melakukan safety } \\
\text { talk sebelum kerja }\end{array}$ \\
\hline & $\begin{array}{l}\text { Posisi tubuh } \\
\text { yang salah } \\
\text { sehingga } \\
\text { berbenturan } \\
\text { dengan tangga }\end{array}$ & Terbentur & 1 & 2 & 3 & 6 & Acceptable & $\begin{array}{l}\text { Memakai helmet, safety } \\
\text { shoes, memasangkan warning } \\
\text { sign dan safety line di area } \\
\text { kerja serta melakukan safety } \\
\text { talk sebelum kerja }\end{array}$ \\
\hline & $\begin{array}{l}\text { Kondisi tangga } \\
\text { yang tidak } \\
\text { kuat, dan tidak } \\
\text { berpegangan } \\
\text { pada tangga }\end{array}$ & Terjatuh & 50 & 2 & 3 & 300 & Priority 1 & $\begin{array}{l}\text { Merapikan kabel yang } \\
\text { berserakan di area kerja agar } \\
\text { tidak mengganggu akses } \\
\text { jalan, memasang warning } \\
\text { sign dan house keeping rutin, } \\
\text { safety talk sebelum kerja, } \\
\text { safety belt body harness }\end{array}$ \\
\hline & $\begin{array}{l}\text { Saat menaiki } \\
\text { unit kerja } \\
\text { pengelasan } \\
\text { terjatuh } \\
\text { sehingga } \\
\text { menimpa } \\
\text { pekerja }\end{array}$ & Tertimpa & 15 & 2 & 3 & 90 & Substantial & $\begin{array}{l}\text { Koordinasi dengan pekerja } \\
\text { lain, konsentrasi dan berhati- } \\
\text { hati saat kerja serta memakai } \\
\text { wear pack, helmet, safety } \\
\text { shoes, sarung tangan }\end{array}$ \\
\hline \multicolumn{9}{|c|}{ Tahap Pengerjaan Pengelasan } \\
\hline \multirow{4}{*}{$\begin{array}{l}\text { Melakukan } \\
\text { pengelasan } \\
\text { dengan las }\end{array}$} & $\begin{array}{l}\text { Posisi jari } \\
\text { tangan yang } \\
\text { salah saat } \\
\text { menjepit } \\
\text { elektroda }\end{array}$ & Terjepit & 1 & 2 & 3 & 6 & Acceptable & $\begin{array}{l}\text { Arahkan tangan dengan } \\
\text { posisi yang benar, memakai } \\
\text { goggles, sarung tangan, dan } \\
\text { helmet }\end{array}$ \\
\hline & $\begin{array}{l}\text { Kondisi } \\
\text { kabel yang } \\
\text { tidak terawat } \\
\text { (terkelupas), } \\
\text { area kerja basah }\end{array}$ & $\begin{array}{l}\text { Tersengat } \\
\text { Listrik }\end{array}$ & 50 & 1 & 3 & 150 & Substantial & $\begin{array}{l}\text { Dipasang papan pijakan } \\
\text { untuk jalan, memakai sarung } \\
\text { tangan, safety shoes, helmet, } \\
\text { wear pack pemeliharaan } \\
\text { peralatan secara berkala }\end{array}$ \\
\hline & $\begin{array}{l}\text { Percikan api las } \\
\text { mengenai bahan } \\
\text { yang mudah } \\
\text { terbakar }\end{array}$ & Terbakar & 50 & 1 & 6 & 300 & Substantial & $\begin{array}{l}\text { Sediakan APAR dan } \\
\text { menyediakan tempat untuk } \\
\text { peralatan dan material yang } \\
\text { mudah terbakar. Memasang } \\
\text { warning sign, wear pack dan } \\
\text { sarung tangan }\end{array}$ \\
\hline & $\begin{array}{l}\text { Kondisi tempat } \\
\text { kerja yang licin }\end{array}$ & Terjatuh & 50 & 2 & 3 & 300 & Priority 1 & $\begin{array}{l}\text { Merapikan kabel yang } \\
\text { berserakan di area kerja agar } \\
\text { tidak mengganggu akses } \\
\text { jalan, memasang warning } \\
\text { sign dan house keeping rutin. } \\
\text { Safety talk sebelum kerja, } \\
\text { safety belt body harness }\end{array}$ \\
\hline
\end{tabular}




\begin{tabular}{|c|c|c|c|c|c|c|c|c|}
\hline $\begin{array}{l}\text { Melakukan } \\
\text { perapian dengan } \\
\text { palu terak }\end{array}$ & $\begin{array}{l}\text { Saat melakukan } \\
\text { perapian dengan } \\
\text { palu terak }\end{array}$ & $\begin{array}{l}\text { Terpukul } \\
\text { dan } \\
\text { terkena } \\
\text { percikan } \\
\text { material }\end{array}$ & 1 & 2 & 10 & 20 & Acceptable & $\begin{array}{l}\text { Memakai goggles, face } \\
\text { shield, helmet, safety } \\
\text { shoes, sarung tangan dan } \\
\text { harus memakai wear pack } \\
\text { pelindung }\end{array}$ \\
\hline \multirow{4}{*}{$\begin{array}{l}\text { Merapikan } \\
\text { material kerja } \\
\text { yang dilas } \\
\text { dengan mesin } \\
\text { gerinda }\end{array}$} & $\begin{array}{l}\text { Posisi jari } \\
\text { tangan yang } \\
\text { salah }\end{array}$ & Tergores & 5 & 3 & 3 & 45 & Priority 3 & $\begin{array}{l}\text { Menjaga jarak aman saat } \\
\text { bekerja, konsentrasi, dan } \\
\text { berhati-hati saat bekerja, } \\
\text { memakai wear pack, helmet, } \\
\text { safety shoes, dan sarung } \\
\text { tangan }\end{array}$ \\
\hline & $\begin{array}{l}\text { Percikan api } \\
\text { dari benda kerja }\end{array}$ & $\begin{array}{l}\text { Terkena } \\
\text { percikan } \\
\text { api }\end{array}$ & 1 & 3 & 10 & 30 & Priority 3 & $\begin{array}{l}\text { Memakai goggles, face } \\
\text { shield, helmet, safety } \\
\text { shoes, sarung tangan dan } \\
\text { harus memakai wear pack } \\
\text { pelindung }\end{array}$ \\
\hline & $\begin{array}{l}\text { Posisi kabel } \\
\text { yang tidak rapi }\end{array}$ & Terjatuh & 1 & 10 & 3 & 30 & Priority 3 & $\begin{array}{l}\text { Merapikan kabel yang } \\
\text { berserakan di area kerja agar } \\
\text { tidak mengganggu akses } \\
\text { jalan, memasang warning } \\
\text { sign dan house keeping rutin, } \\
\text { safety talk sebelum kerja, } \\
\text { safety belt body harness }\end{array}$ \\
\hline & $\begin{array}{l}\text { Kabel } \\
\text { terkelupas atau } \\
\text { tidak terpelihara }\end{array}$ & $\begin{array}{l}\text { Tersengat } \\
\text { listrik }\end{array}$ & 15 & 1 & 3 & 45 & Priority 3 & $\begin{array}{l}\text { Dipasang papan pijakan } \\
\text { untuk jalan, memakai sarung } \\
\text { tangan, safety shoes, helmet, } \\
\text { wear pack pemeliharaan } \\
\text { peralatan secara berkala }\end{array}$ \\
\hline $\begin{array}{l}\text { Membersihkan } \\
\text { tempat kerja dari } \\
\text { serpihan material } \\
\text { kerja }\end{array}$ & $\begin{array}{l}\text { Potongan atau } \\
\text { serpihan benda } \\
\text { tajam yang } \\
\text { tajam }\end{array}$ & Tertusuk & 1 & 2 & 6 & 12 & Acceptable & $\begin{array}{l}\text { Memakai helmet, safety } \\
\text { shoes, sarung tangan dan } \\
\text { harus memakai wear pack } \\
\text { pelindung }\end{array}$ \\
\hline \multirow{2}{*}{$\begin{array}{l}\text { Turun tangga/ } \\
\text { scaffolding }\end{array}$} & $\begin{array}{l}\text { Kondisi tangga } \\
\text { licin karena } \\
\text { air, tidak } \\
\text { berpegangan } \\
\text { pada tangga }\end{array}$ & Terjatuh & 50 & 2 & 3 & 300 & Priority 1 & $\begin{array}{l}\text { Merapikan kabel yang } \\
\text { berserakan di area kerja agar } \\
\text { tidak mengganggu akses } \\
\text { jalan, memasang warning } \\
\text { sign dan house keeping rutin. } \\
\text { Safety talk sebelum kerja, } \\
\text { safety belt body harness }\end{array}$ \\
\hline & $\begin{array}{l}\text { Saat } \\
\text { menurunkan } \\
\text { unit pengelasan } \\
\text { terjatuh } \\
\text { mengenai } \\
\text { pekerja }\end{array}$ & Tertimpa & 15 & 2 & 3 & 90 & Substantial & $\begin{array}{l}\text { Koordinasi dengan pekerja } \\
\text { lain, konsentrasi dan berhati- } \\
\text { hati saat kerja serta memakai } \\
\text { wear pack, helmet, safety } \\
\text { shoes, sarung tangan }\end{array}$ \\
\hline
\end{tabular}


Tabel 4. Analisis Risiko Keselamatan Pengelasan pada Tempat Tertutup dengan Las

\begin{tabular}{|c|c|c|c|c|c|c|c|c|}
\hline \multirow{2}{*}{ Tahap Pekerjaan } & \multirow{2}{*}{$\begin{array}{c}\text { Identifikasi } \\
\text { Bahaya }\end{array}$} & \multirow{2}{*}{ Bahaya } & \multicolumn{4}{|c|}{ Analisis Risiko } & \multirow{2}{*}{ Kategori } & \multirow{2}{*}{ Pengendalian } \\
\hline & & & $\mathbf{C}$ & $\mathbf{E}$ & $\mathbf{L}$ & Skor & & \\
\hline \multicolumn{9}{|c|}{ Tahap Persiapan Pengelasan } \\
\hline \multirow{2}{*}{$\begin{array}{l}\text { Memasuki ruang } \\
\text { tertutup }\end{array}$} & $\begin{array}{l}\text { Kondisi } \\
\text { tempat kerja } \\
\text { licin }\end{array}$ & Terpeleset & 1 & 2 & 6 & 12 & Acceptable & $\begin{array}{l}\text { Memakai helmet, } \\
\text { safety shoes, sarung } \\
\text { tangan memasangkan } \\
\text { warning sign dan safety } \\
\text { line di area kerja serta } \\
\text { melakukan safety talk } \\
\text { sebelum kerja }\end{array}$ \\
\hline & $\begin{array}{l}\text { Tubuh } \\
\text { berbenturan } \\
\text { dengan } \\
\text { tempat kerja }\end{array}$ & Terbentur & 1 & 2 & 6 & 12 & Acceptable & $\begin{array}{l}\text { Memakai helmet, } \\
\text { safety shoes wear } \\
\text { pack, memasangkan } \\
\text { warning sign dan safety } \\
\text { line di area kerja serta } \\
\text { melakukan safety talk } \\
\text { sebelum kerja }\end{array}$ \\
\hline \multicolumn{9}{|c|}{ Tahap Pengerjaan Pengelasan } \\
\hline \multirow{4}{*}{$\begin{array}{l}\text { Melakukan } \\
\text { pengelasan }\end{array}$} & $\begin{array}{l}\text { Terdapat gas } \\
\text { beracun }\end{array}$ & Keracunan & 15 & 2 & 6 & 180 & Priority 1 & $\begin{array}{l}\text { Koordinasi dengan } \\
\text { K3 dan Hiperkes bila } \\
\text { perlu, dipasang ventilasi } \\
\text { exhaust fan, work permit } \\
\text { dari K3, wear pack, } \\
\text { helmet, masker standar } \\
\mathrm{K} 3 \text {, safety talk }\end{array}$ \\
\hline & $\begin{array}{l}\text { Kondisi } \\
\text { kabel yang } \\
\text { tidak terawat } \\
\text { (terkelupas) } \\
\text { area kerja } \\
\text { basah }\end{array}$ & $\begin{array}{l}\text { Tersengat } \\
\text { listrik }\end{array}$ & 50 & 1 & 3 & 150 & Substantial & $\begin{array}{l}\text { Dipasang papan pijakan } \\
\text { untuk jalan, memakai } \\
\text { sarung tangan, safety } \\
\text { shoes, helmet, wear pack } \\
\text { pemeliharaan peralatan } \\
\text { secara berkala }\end{array}$ \\
\hline & $\begin{array}{l}\text { Kondisi } \\
\text { panas } \\
\text { menyebabkan } \\
\text { dehidrasi }\end{array}$ & Pingsan & 5 & 2 & 6 & 60 & Priority 3 & $\begin{array}{l}\text { Koordinasi dengan } \\
\text { K3 dan Hiperkes bila } \\
\text { perlu, dipasang ventilasi } \\
\text { exhaust fan, work permit } \\
\text { dari K3, wear pack, } \\
\text { helmet, masker standar } \\
\mathrm{K} 3 \text {, safety talk }\end{array}$ \\
\hline & $\begin{array}{l}\text { Posisi kabel } \\
\text { yang tidak } \\
\text { rapi, terjatuh }\end{array}$ & Terjatuh & 1 & 2 & 3 & 6 & Acceptable & $\begin{array}{l}\text { Merapikan kabel yang } \\
\text { berserakan di area kerja } \\
\text { agar tidak mengganggu } \\
\text { akses jalan, memasang } \\
\text { warning sign dan house } \\
\text { keeping rutin, safety talk } \\
\text { sebelum kerja, safety belt } \\
\text { body harness }\end{array}$ \\
\hline
\end{tabular}




\begin{tabular}{|c|c|c|c|c|c|c|c|c|}
\hline \multicolumn{9}{|c|}{ Tahap Perapian dan Finishing } \\
\hline $\begin{array}{l}\text { Melakukan } \\
\text { perapian dengan } \\
\text { palu terak }\end{array}$ & $\begin{array}{l}\text { Saat } \\
\text { melakukan } \\
\text { perapian } \\
\text { dengan palu } \\
\text { terak }\end{array}$ & $\begin{array}{l}\text { Terpukul } \\
\text { dan } \\
\text { terkena } \\
\text { percikan } \\
\text { material }\end{array}$ & 1 & 2 & 10 & 20 & Priority 3 & $\begin{array}{l}\text { Memakai goggles, face } \\
\text { shield, helmet, safety } \\
\text { shoes, sarung tangan dan } \\
\text { harus memakai wear } \\
\text { pack pelindung }\end{array}$ \\
\hline \multirow{4}{*}{$\begin{array}{l}\text { Merapikan } \\
\text { material kerja } \\
\text { yang dilas dengan } \\
\text { mesin gerinda }\end{array}$} & $\begin{array}{l}\text { Posisi jari } \\
\text { tangan yang } \\
\text { salah }\end{array}$ & Tergores & 5 & 3 & 3 & 45 & Priority 3 & $\begin{array}{l}\text { Menjaga jarak aman saat } \\
\text { bekerja, konsentrasi, da } \\
\text { berhati-hati saat bekerja, } \\
\text { memakai wear pack, } \\
\text { helmet, safety shoes, dan } \\
\text { sarung tangan }\end{array}$ \\
\hline & $\begin{array}{l}\text { Percikan api } \\
\text { dari benda } \\
\text { kerja }\end{array}$ & $\begin{array}{l}\text { Terkena } \\
\text { percikan } \\
\text { api }\end{array}$ & 1 & 3 & 10 & 30 & Priority 3 & $\begin{array}{l}\text { Memakai goggles, face } \\
\text { shield, helmet, safety } \\
\text { shoes, sarung tangan dan } \\
\text { harus memakai wear } \\
\text { pack pelindung }\end{array}$ \\
\hline & $\begin{array}{l}\text { Posisi kabel } \\
\text { yang tidak } \\
\text { rapi }\end{array}$ & Terjatuh & 1 & 10 & 3 & 30 & Priority 3 & $\begin{array}{l}\text { Merapikan kabel yang } \\
\text { berserakan di area kerja } \\
\text { agar tidak mengganggu } \\
\text { akses jalan, memasang } \\
\text { warning sign dan house } \\
\text { keeping rutin. Safety talk } \\
\text { sebelum kerja, safety belt } \\
\text { body harness }\end{array}$ \\
\hline & $\begin{array}{l}\text { Kabel } \\
\text { terkelupas } \\
\text { atau tidak } \\
\text { terpelihara }\end{array}$ & $\begin{array}{l}\text { Tersengat } \\
\text { listrik }\end{array}$ & 15 & 1 & 3 & 45 & Priority 3 & $\begin{array}{l}\text { Dipasang papan pijakan } \\
\text { untuk jalan, memakai } \\
\text { sarung tangan, safety } \\
\text { shoes, helmet, wear pack } \\
\text { pemeliharaan peralatan } \\
\text { secara berkala }\end{array}$ \\
\hline $\begin{array}{l}\text { Membersihkan } \\
\text { tempat kerja dari } \\
\text { serpihan material } \\
\text { kerja }\end{array}$ & $\begin{array}{l}\text { Potongan } \\
\text { atau serpihan } \\
\text { benda tajam } \\
\text { yang tajam }\end{array}$ & Tertusuk & 1 & 2 & 6 & 12 & Acceptable & $\begin{array}{l}\text { Memakai helmet, safety } \\
\text { shoes, sarung tangan dan } \\
\text { harus memakai wear } \\
\text { pack pelindung }\end{array}$ \\
\hline \multirow{2}{*}{$\begin{array}{l}\text { Keluar dari ruang } \\
\text { tertutup }\end{array}$} & $\begin{array}{l}\text { Kondisi } \\
\text { tempat kerja } \\
\text { licin }\end{array}$ & Terpeleset & 1 & 2 & 6 & 12 & Acceptable & $\begin{array}{l}\text { Memakai helmet, } \\
\text { safety shoes, sarung } \\
\text { tangan memasangkan } \\
\text { warning sign dan safety } \\
\text { line di area kerja serta } \\
\text { melakukan safety talk } \\
\text { sebelum kerja }\end{array}$ \\
\hline & $\begin{array}{l}\text { Tubuh } \\
\text { bertubruk } \\
\text { dengan } \\
\text { material dan } \\
\text { alat kerja }\end{array}$ & Terbentur & 1 & 2 & 6 & 12 & Acceptable & $\begin{array}{l}\text { Memakai helmet, } \\
\text { safety shoes wear } \\
\text { pack, memasangkan } \\
\text { warning sign dan safety } \\
\text { line di area kerja serta } \\
\text { melakukan safety talk } \\
\text { sebelum kerja }\end{array}$ \\
\hline
\end{tabular}




\section{PEMBAHASAN}

Data primer didapat melalui wawancara yaitu pencarian informasi langsung dari lapangan tentang penyebab risiko bahaya pengelasan kepada pekerja dan supervisor atau kepada safety officer maupun operator yang berhubungan langsung dengan pekerjaan tersebut, pengambilan foto pada aktivitas-aktivitas pengelasan yang dilakukan di lokasi pembuatan kapal baru dan kemudian mengidentifikasi potensi bahaya yang ada. Untuk memperkuat penelitian maka dari itu melihat JSA dari sumber yang lain dengan kasus yang sama yaitu pengelasan di sebuah perusahaan perkapalan yang berada di Indonesia maupun di luar negeri sehingga dalam memberikan penilaian risiko ini dapat dipertanggungjawabkan.

Pada tahap mengidentifikasi bahaya yang dilakukan bahwa potensi bahaya yang ada di setiap aktivitas pengelasan berdasarkan bahaya mekanik, bahaya elektrik dan bahaya kimia yaitu: 1. Bahaya mekanik antara lain terbentur material kerja, tergores benda tajam atau material kerja, terpeleset di tempat kerja, terjatuh akibat terpeleset dan terjatuh dari ketinggian, terjepit material kerja, terpukul palu terak dan tertimpa material kerja. 2. Bahaya elektrik antara lain tersengat arus listrik, terkena percikan api dan serpihan potongan besi. 3. Bahaya kimia antara lain terkena percikan api pada tubuh, terjadi kebakaran akibat tabung gas bocor, adanya ledakan dan bahan beracun.

Berikut ini merupakan hasil laporan penelitian dengan menggunakan metode JSA. Hasil analisis tingkat risiko bahaya keselamatan kerja pada tabel 1 menunjukkan bahwa identifikasi, penilaian risiko pada pekerjaan pengelasan pada ruang terbuka, didapatkan risiko bahaya yang tertinggi yaitu tersengat arus listrik pada tempat yang basah dan pada tempat yang kering terjadi electric shock dengan nilai skor 300 termasuk kategori priority 1, maka perlu adanya tindakan pengendalian sesegera mungkin. Kategori substantial antara lain: terkena percikan api pada tubuh, terkena percikan serpihan benda tajam pada mata. Kategori priority 3 antara lain: terbentur material benda, terjatuh pada tempat kerja, terjepit holder las, tergores benda dan material kerja. Hasil observasi pada pengelasan di ruang terbuka masih ditemukan unsafe condition seperti benda kerja tidak tertata rapi, kabel-kabel yang berserakan sehingga mengganggu akses jalan, panel box listrik yang tidak terawat dengan baik, pengaturan ruang kerja yang terlalu sempit, barang-barang kapal yang menumpuk di tempat kerja, ventilasi yang kurang bagus di tempat kerja dapat menyebabkan dehidrasi para pekerja, tidak ada pengatur suhu dan tidak terdapat alat pemadam kebakaran di tempat kerja. Sebagian pekerja pengelasan telah mempunyai kesadaran menggunakan alat pelindung diri, tetapi masih ditemukan unsafe act seperti pekerja yang tidak menggunakan alat pelindung diri saat bekerja.

Hasil tabel 2 pada analisis tingkat risiko keselamatan kerja pengelasan di tempat ketinggian dengan menunjukkan bahwa identifikasi dan penilaian risiko pada tempat ketinggian didapatkan bahaya yang tertinggi yaitu terjatuh dari ketinggian lebih dari 1,5 meter dengan skor 300 termasuk kategori priority 1. Kategori substantial yaitu tertimpa material kerja, tersengat arus listrik, terbakar pada tubuh dan lingkungan kerja. Sedang kategori acceptable yaitu terpeleset dari tempat kerja, terbentur material kerja, terjepit arde las dan material kerja, terpukul palu terak dan terkena percikan api las, dan tertusuk serpihan baja.

Hasil tabel 3 pada analisis tingkat risiko keselamatan kerja pengelasan di ruang tertutup dengan menunjukkan bahwa identifikasi dan penilaian risiko pada ruang tertutup didapatkan bahaya yang tertinggi yaitu keracunan gas 180 yang termasuk priority 1. Kategori risiko substantial yaitu tersengat arus listrik, tidak sadarkan diri, terpukul palu terak dan terkena percikan api las maupun percikan serpihan material kecil termasuk kategori priority 3. Pada kategori risiko acceptable yaitu terpeleset di tempat kerja, terbentur material kerja, dan terjepit arde las. Setelah melakukan identifikasi bahaya, penilaian terhadap risiko bahaya di tempat kerja maka tahap selanjutnya pada pengelasan perkapalan dengan pendekatan job safety analysis yaitu melakukan pengendalian. Pengendalian merupakan proses untuk memastikan bahwa aktivitas sebenarnya sesuai dengan aktivitas yang direncanakan pengendalian adalah suatu proses dengan memastikan pada setiap kegiatan yang sesungguhnya sudah sesuai dengan perencanaan. Pengendalian bagian penting dalam usaha pencegahan kecelakaan sehingga penting untuk tindakan korektif sesuai kebutuhan.

Pengendalian risiko diperlukan untuk mengamankan pekerja dari bahaya yang ada di tempat kerja sesuai dengan persyaratan kerja. Pada pelaksanaan K3 akan terwujud perlindungan untuk pekerja terhadap bahaya risiko di tempat kerja maka perlu didukung oleh komitmen manajemen, sumber 
daya manusia dan teknologi yang mendukung agar pelaksanaan pengendalian risiko bahaya dapat terwujud. Sejalan dengan itu, K3 yang efektif akan dapat meningkatkan produktivitas pekerja dan kemudian akan meningkatkan hasil produksi. Manajemen perusahaan yang sistematis dan terintegrasi akan memberikan dampak mengurangi atau menghilangkan risiko kecelakaan di tempat kerja sehingga menghasilkan lingkungan kerja yang aman dan bebas dari ancaman bahaya di tempat kerja.

Sistem manajemen keselamatan dan kesehatan kerja yang diimplementasikan menjadi program K3 yang dilakukan oleh PT DUMAS Tanjung Perak Shipyards yaitu pembinaan dan pengawasan. Melalui pembinaan K3 bertujuan memasyarakatkan dan meningkatkan kesadaran seluruh pekerja tentang budaya K3 selamat di lingkungan kerja contohnya: melakukan safety induction ditujukan bagi pekerja yang baru maupun pekerja pindahan untuk memasuki daerah kegiatan pengelasan, safety talk dilaksanakan pada setiap hari Senin dan Jumat pada saat sebelum memulai kegiatan, safety campaign adalah merupakan kegiatan pemasangan banner, posterposter yang berisikan pesan-pesan $\mathrm{K} 3$ diharapkan dengan adanya poster-poster tersebut para pekerja tertarik membaca dan mengimplentasikan dalam pekerjaannya, dan melaksanakan rapat P2K3 setiap akhir bulan membahas permasalahan yang terjadi dan dilakukan perbaikan. Melalui hasil temuan dari safety patrol dan inspeksi.

Pengawasan K3 yang dilakukan oleh perusahaan yaitu, inspeksi merupakan pengecekan yang dilakukan oleh pihak P2K3 untuk menemukan ketidaksesuaian pekerjaan dengan standar prosedur kerja. Tujuan utama dari inspeksi mengidentifikasi dan mengontrol bahaya di tempat kerja sehingga menimbulkan efek keselamatan dan kesehatan kerja. Safety work permit dilakukan pada aktivitas yang mempunyai risiko tinggi dan adanya permintaan unit kerja agar dilakukan pengawasan saat bekerja. Audit $\mathrm{K} 3$, terdiri dari audit $\mathrm{K} 3$ internal dan audit eksternal. Hasil pengawasan dan inspeksi di lapangan akan dituangkan dalam sebuah data yang berupa tabel JSA.

Berdasarkan hierarki pengendalian, usaha pengendalian pada pekerjaan pengelasan PT. DUMAS Tanjung Perak Shipyard yaitu pengendalian engineering control. Pada pengelasan di PT. DUMAS Tanjung Perak Shipyard pengendalian yang termasuk engineering control yaitu membuat papan pijakan untuk akses jalan ketika keadaan area kerja basah, memasang safety line di area kerja yang berbahaya, menyediakan ruangan untuk tempat penyimpanan material dan peralatan kerja yang mudah terbakar, merapikan kabel-kabel yang berserakan agar tidak mengganggu akses jalan, pemasangan scaffolding yang sesuai dengan standar K3, memberikan ventilasi yang cukup untuk ruangan pekerjaan tertutup misalnya exhaust fan dan blower.

Pengendalian yang termasuk administrative control pada pengelasan yaitu warning sign yang dipasang di wilayah kerja, dilakukan safety talk sebelum melakukan pekerjaan, komunikasi dengan sesama pekerja, koordinasi dengan pihak K3 work permit untuk pengelasan di tempat berbahaya, adanya standar operasi baku pada tiap pekerjaan, seleksi karyawan untuk melakukan pekerjaan tertentu, melakukan safety patrol dan inspeksi lapangan dilakukan pelatihan pada pekerjaan tertentu, pemeliharaan peralatan kerja, melakukan kalibrasi alat-alat kerja,

Pengendalian dengan menggunakan alat pelindung diri. Adapun bentuk alat pelindung diri yang disediakan oleh perusahaan adalah: safety helmet, safety belt, safety shoes, sarung tangan, safety harness, ear plug/ear muff, masker dan masker respiro, safety spectacles, goggles, face shields.

Rekomendasi yang dapat diberikan pada penelitian pada pekerjaan pengelasan adalah dengan membuat jadwal sosialisasi K3 dengan mengkampanyekan budaya bekerja dengan selamat setiap hari ketika memulai bekerja, memberikan tempat untuk menaruh barang-barang pekerja, melakukan pengecekan kelengkapan alat pelindung diri ketika mau masuk kerja, menyediakan fasilitas untuk makan, istirahat dan melakukan ibadah untuk para pekerja, menyediakan alat pelindung diri yang sesuai dengan divisi pekerjaan, memberikan penghargaan dan sanksi yang jelas pada pekerja, memberikan gizi pekerja, menjaga housekeeping dengan baik, membuat poster mengenai larangan merokok di tempat kerja, membuat Management Safety Data Sheets (MSDS) pada setiap material yang digunakan, bekerja dengan hati-hati dan koordinasi dengan pihak K3, mengatur jarak aman untuk material dengan mesin kerja, melakukan program pemeriksaan kesehatan dengan cara melakukan pemeriksaan kesehatan awal, khusus, dan pemeriksaan kesehatan secara berkala, dan membatasi usia kerja yang seharusnya bekerja atau tidak. 


\section{SIMPULAN}

Hasil analisis risiko keselamatan kerja pada pekerjaan pengelasan di tempat tertutup, tempat terbuka dan pada tempat di ketinggian PT. DUMAS Tanjung Perak Shipyards didapatkan risiko bahaya antara lain: terbentur material kerja, terpeleset dari tempat kerja, kesetrum listrik, jatuh dari tempat ketinggian, terjepit grounding las, percikan api las mengenai tubuh, terkena percikan serpihan besi, terbakar, tergores material kerja, tertusuk benda tajam serpihan besi, tertimpa material kerja, keracunan gas, dan sampai tidak sadarkan diri.

Tingkat risiko pada pekerja pengelasan di PT DUMAS Tanjung Perak Shipyards yaitu: (a.) Priority 1: Pengelasan di tempat terbuka memakai las listrik yaitu kesetrum listrik. Pengelasan pada tempat tertutup yaitu kesetrum listrik dan keracunan gas. Pengelasan pada ketinggian dengan memakai las listrik yaitu kesetrum listrik dan jatuh dari ketinggian lebih dari 1,5 meter (b.) Substantial: Pengelasan pada tempat terbuka dengan las listrik, kesetrum listrik di tempat kering, terkena percikan api las dan material kerja, terbakar, terjepit benda kerja dan kejatuhan material kerja. Pengelasan pada tempat tertutup dengan las listrik yaitu kesetrum di tempat kering dan pengelasan di tempat ketinggian dengan las listrik yaitu kesetrum listrik pada area kering dan keruntuhan material kerja (c.) Prioritas 3: Pengelasan di ruang terbuka dengan las listrik yaitu tertubruk material kerja, terjepit grounding holder, jatuh dari tempat ketinggian, tergores material kerja, terpukul palu terak, tertusuk serpihan besi, terpotong ketika menggunakan alat gerinda, electric shock, dan terkena percikan api dan serpihan besi ketika tahap perapian dengan menggunakan alat gerinda. Pengelasan pada ketinggian dengan las listrik yaitu terkena percikan api las, dan terkena percikan benda kerja saat menggunakan palu terak. Pengelasan pada tempat tertutup tergores material kerja, terpukul palu terak, tertusuk serpihan besi, terpotong ketika menggunakan alat gerinda, electric shock, dan terkena percikan api dan serpihan besi ketika tahap perapian dengan menggunakan alat gerinda (d.) Acceptable: Pengelasan pada tempat terbuka dengan las listrik yaitu terpeleset, terjepit dan tertubruk pada saat mempersiapkan tabung gas. Pengelasan pada tempat tertutup dengan las listrik yaitu terpeleset dari tempat kerja, tertubruk material dan alat kerja, tergores material kerja, dan tertusuk benda tajam besi. Pengelasan di tempat ketinggian dengan las listrik yaitu terpeleset dari tempat kerja, terbentur material kerja, terjepit alat holder las, tergores material kerja, terpukul palu terak dan tertusuk serpihan besi yang tajam.

Pengendalian yang dilakukan oleh PT DUMAS Tanjung Perak Shipyards adalah dengan engineering control, administrative control, dan alat pelindung diri.

\section{DAFTAR PUSTAKA}

Andryansyah. 2000. Keselamatan dan Kesehatan Kerja Pengelasan dalam Ruang Terbatas. Jurnal Keselamatan dan Kesehatan Kerja Volume 01, hal. 52-55.

Anggoro, W., dan K, Dewi. 1999. Keselamatan Kerja pada Proses Pengelasan di Laboratorium Proses Produksi FTI-UAJ. Jurnal Teknologi Industri Volume, hal. 111-118.

BSN. 2008. Sistem Manajemen Mutu-Persyaratan. SNI ISO 9001-2008.

DKEN. Visi, Misi, Kebijakan, Strategi dan Program Kerja K3 Nasional 2007-2010. Jakarta: DK3N, 2007.

ILO. 1996. Introduction to Occupational Health and Safety.

Mariana, Y. 2009. Pengembangan Dokumen Hazard Identification Risk Assessment and Risk Control di PT. Schneider Electric Indonesia berdasarkan standar OHSAS 18001: 2007, Skripsi, Teknik Industri, Universitas Kristen Petra.

Mulya, A. 2008. Analisis dan Pengendalian Risiko Keselamatan Kerja dengan Metode Semi Kuantitatif pada Pekerja di PT. ANTAM EMAS Bogor tahun 2008. Skripsi, Jurusan Kesehatan Masyarakat, Jakarta.

Peraturan Menteri Tenaga Kerja dan Transmigrasi Nomor 04/MEN/1980. Tentang Syaratsyarat Pemasangan dan Pemeliharaan Alat Pemadam Api Ringan. Menteri Tenaga Kerja dan Transmigrasi.

Putri, M. 2011. Analisis Pelaksanaan JSA pada Pekerjaan Wellwork dan Initial Completion Kontraktor Migas di PT. X Tahun 2011, Skripsi, Jurusan Kesehatan Masyarakat, UIN.

Ramli, S. 2010. Sistem Manajemen Keselamatan dan Kesehatan Kerja OHSAS 18001. Jakarta: PT. Dian Rakyat.

Ridley, J. 2006. Keselamatan dan Kesehatan Kerja Edisi Ketiga. Jakarta: Erlangga.

Suma'mur. 1981. Keselamatan dan Pencegahan Kecelakaan. Jakarta: PT. Gunung Agung. 
Susanto, A. 2006. Kebisingan serta Pengaruhnya terhadap Kesehatan dan Lingkungan. Binary moon: Bandung.

The Australian Standart/New Zealand Standard (AS/ NZS 4360: 2004). Risk Management Guideline, 1999.
Undang-Undang Republik Indonesia No. 1 Tahun 1970. Tentang Keselamatan Kerja UU Republik Indonesia No. 13 Tahun 2003. Tentang Ketenagakerjaan. 